\title{
Muere eminente pensador Adolfo Sánchez Vásquez.
}

\author{
Recibido: 14 de julio de 2011 / 15 de julio de 2011
}

\section{RESUMEN}

Se informa sobre la muerte de Adolfo Sánchez Vásquez, uno de los más relevantes filósofos contemporáneos, señalándose la relación de amistad con Nicaragua y su pertenencia al Consejo de Colaboradores Internacionales de la Revista "Cultura de Paz".

Palabras clave: filosofia, estética, marxismo, Nicaragua, Cultura de Paz.

\section{ABSTRACT}

We inform on the death of Adolfo Sánchez Vásquez, one of the most important contemporary philosophers. He had a great friendship with Nicaragua and was a member of International Contributors Board of the "Culture of Peace" Magazine.

Keywords: philosophy, aesthetics, Marxism, Nicaragua, Culture of Peace.
工 amentamos informar a nuestros lectores que el 08 de julio, murió el destacado filósofo marxista, españolmexicano, Adolfo Sánchez Vásquez. Considerado uno de los filósofos más importantes del siglo XX, contribuyó a la renovación del marxismo, promoviendo un socialismo crítico y democrático. Entre sus obras más relevantes que influyeron en muchas generaciones de intelectuales latinoamericanos cabe señalar: Las ideas estéticas de Marx. Del socialismo científico al socialismo utópico, Cuestiones estéticas y artísticas contemporáneas, Ensayos sobre filosofía e ideología y muchos otros escritos sobre filosofía, estética, lógica e historia de la filosofía.

Adolfo Sánchez Vásquez, nació en España en 1915, vivió lo más intenso de la guerra civil española, dirigiendo en esos años, siendo aún muy joven, el periódico de las juventudes socialistas de España. Refiriéndose a esa época de su vida, compartió con colegas de nuestro Consejo Editorial, con quienes recordó que dada su admiración por la poesía nicaragüense, publicó a varios de nuestros grandes poetas de entonces, en plena guerra civil.

Sánchez Vásquez fue muy amigo de la Nicaragua revolucionaria, junto a otros intelectuales prominentes, como Gregorio Selser, Pablo González Casanova, Vlady, Elena Poniatowska, Leopoldo Zea, entre otros y mantuvo expresiones concretas de condena a la agresión que vivió el país en los años 80. Como expresión de su solidaridad con nuestro pueblo, prologó en el año 1987, la obra "Conflicto y paz, el proceso negociador centroamericano" del entonces Vicecanciller de la República, Dr. Victor Hugo Tinoco.

Adolfo Sánchez Vásquez, atento a respaldar y promover toda iniciativa de vanguardia del pensamiento progresista universal, desde su fundación formó parte del Consejo Internacional de Colaboradores de nuestra Revista "Cultura de Paz". Junto a Zea, Vlady y ahora Sánchez Vásquez, la Revista "Cultura de Paz", ha perdido a 3 colaboradores relevantes del pensamiento latinoamericano y mundial. Como homenaje a su memoria, en el próximo número se publicará un ensayo sobre una de sus últimas obras.

A su familia, a la UNAM, en la cual fue profesor emérito y en la cual uno de sus recientes pabellones lleva su nombre, les manifestamos nuestra solidaridad, reconocimiento y acompañamiento.

Denis Torres

Director Instituto "Martin Luther King”-UPOLI 